\title{
Traditional Chinese Medicine Xihuang Wan Inhibited Lewis Lung Carcinoma in a Syngeneic Model, Equivalent to Cytotoxic Chemotherapy, by Altering Multiple Signaling Pathways
}

\author{
ZHIYING ZHANG ${ }^{1,2,3,4}$, JIANFENG WANG $^{1,2}$, HUA DUAN $^{1,2}$, DIANNA LIU $^{1,2}$, XIANGNAN ZHOU $^{1,2}$, XIMING LIN $^{1,2}$, \\ HAOYUE PANG ${ }^{1,2}$, MANQIANG SUN ${ }^{1,2}$, TIAN ZHOU ${ }^{2}$, ROBERT M. HOFFMAN ${ }^{3,4}$ and KAIWEN HU ${ }^{2}$ \\ ${ }^{1}$ Graduate School, Beijing University of Chinese Medicine, Beijing, P.R. China; \\ ${ }^{2}$ Department of Oncology, Dongfang Hospital, Beijing University of Chinese Medicine, Beijing, P.R. China; \\ ${ }^{3}$ AntiCancer, Inc., San Diego, U.S.A.; \\ ${ }^{4}$ Department of Surgery, University of California, San Diego, U.S.A.
}

\begin{abstract}
Background/Aim: Xihuang Wan (XHW), a traditional Chinese medicine (TCM), has been used in China for a variety of cancers including lung cancer. The present study evaluated the efficacy of XHW on a Lewis lung mouse model and explored the potential mechanism via transcriptomics. Materials and Methods: The mice were randomized into 6 groups: 1) untreated control $(n=10) ; 2)$ low-dose XHW; 3) medium-dose XHW; 4) high-dose XHW; 5) cisplatin; and 6) untreated blank $(n=4)$. Lewis lung carcinoma (LLC) cells were injected subcutaneously except for the 4 mice in the blank group. The body weight and tumor length and width were measured every 3 days. RNAsequencing was performed on tumors in the high-dose XHW group and the control group. Results: XHW inhibited the growth of LLC in a syngeneic mouse model, without toxicity, with equivalent efficacy to cisplatin. RNA-sequencing demonstrated that many signaling pathways were involved in XHW-mediated inhibition of LLC, including tumor necrosis factor, estrogen, cyclic guanosine 3', 5'monophosphate-protein kinase $G$, apelin and the peroxisome proliferator-activated receptor signaling pathways. Conclusion: XHW inhibited LLC carcinoma through different
\end{abstract}

This article is freely accessible online.

Correspondence to: Kaiwen Hu, MD, Ph.D., Dongfang Hospital, Building 6, Fangxing Garden, Fangzhuang, Fengtai District, Beijing, 100078, P.R. China. Tel: +86 13911650713, e-mail: kaiwenh@163.com; Tian Zhou, MD, Ph.D., Dongfang Hospital, Building 6, Fangxing Garden, Fangzhuang, Fengtai District, Beijing, 100078, P.R. China. Tel: +86 13466611847, e-mail: zhoutian_med@163.com

Key Words: Traditional Chinese medicine, Xihuang Wan, lung cancer, syngeneic model, signaling pathway, transcriptome. pathways and shows clinical promise for patients who cannot tolerate platinum-based drugs.

Lung cancer, with an estimated 2.2 million new cases and 1.8 million deaths in 2020, ranks second in incidence and first in mortality among all cancer types throughout the world (1). In China, lung cancer was also the second most commonly diagnosed cancer $(815,563$ cases $)$ and the leading cause of cancer death $(243,153$ cases $)$ in 2020 (2). First-line treatment includes surgery, radiotherapy, chemotherapy, targeted therapy, and immunotherapy $(3,4)$. However, lung cancer still remains recalcitrant.

In China, traditional Chinese medicine (TCM) has been used in clinical practice for thousands of years for a variety of diseases, including benign and malignant tumors (5-8). Xihuang Wan (XHW) was first recorded in the $18^{\text {th }}$-century Chinese medical book Waike Zhengzhi Quansheng Ji (Lifesaving Manual of Diagnosis and Treatment of External Diseases). XHW comprises Ruxiang (Olibanum), Moyao (Myrrha), Niuhuang (Moschus), and Shexiang (Bovis Calculus). XHW has been approved by the National Medical Products Administration (NMPA) of China for the treatment of cancer (approval number Z11020073). In clinical practice, XHW has been used to treat breast (9-12), colorectal (13), liver (14, 15), cervical (16-18), and lung cancer (19-21). A systematic review and meta-analysis showed that XHW combined with chemotherapy enhanced response, prolonged overall survival, improved the quality of life of patients, and alleviated treatment-induced side effects (22).

Our laboratory has previously studied Lewis-lung carcinoma (LLC) in both nude mouse and syngeneic models (23-35). In the present study, we examined the anti-cancer efficacy of XHW in a syngeneic mouse model of LLC, and explored the potential mechanism of XHW by RNAsequencing. 
in vivo $35: 2005-2014(2021)$

Table I. Treatment protocol.

\begin{tabular}{|c|c|c|c|c|}
\hline Group & Treatment & Route & Dose & Frequency \\
\hline 1 Untreated control & $\begin{array}{c}\text { CMC-Na solution } \\
\mathrm{NaCl}\end{array}$ & $\begin{array}{l}\text { p.o. } \\
\text { i.p. }\end{array}$ & $\begin{array}{l}200 \mu \mathrm{l} \\
200 \mu \mathrm{l}\end{array}$ & $\begin{array}{c}\text { Twice a day } \\
\text { Once a week }\end{array}$ \\
\hline 2 Low-dose XHW & $\begin{array}{c}\text { XHW solution } \\
\mathrm{NaCl}\end{array}$ & $\begin{array}{l}\text { p.o. } \\
\text { i.p. }\end{array}$ & $\begin{array}{c}0.617 \mathrm{~g} / \mathrm{kg} \\
200 \mu \mathrm{l}\end{array}$ & $\begin{array}{l}\text { Twice a day } \\
\text { Once a week }\end{array}$ \\
\hline 3 Medium-dose XHW & $\begin{array}{c}\text { XHW solution } \\
\mathrm{NaCl}\end{array}$ & $\begin{array}{l}\text { p.o. } \\
\text { i.p. }\end{array}$ & $\begin{array}{c}1.233 \mathrm{~g} / \mathrm{kg} \\
200 \mu \mathrm{l}\end{array}$ & $\begin{array}{l}\text { Twice a day } \\
\text { Once a week }\end{array}$ \\
\hline 4 High-dose XHW & $\begin{array}{c}\text { XHW solution } \\
\mathrm{NaCl}\end{array}$ & $\begin{array}{l}\text { p.o. } \\
\text { i.p. }\end{array}$ & $\begin{array}{c}2.466 \mathrm{~g} / \mathrm{kg} \\
200 \mu \mathrm{l}\end{array}$ & $\begin{array}{l}\text { Twice a day } \\
\text { Once a week }\end{array}$ \\
\hline 5 Cisplatin & $\begin{array}{c}\text { CMC-Na solution } \\
\text { cisplatin }\end{array}$ & $\begin{array}{l}\text { p.o. } \\
\text { i.p. }\end{array}$ & $\begin{array}{c}200 \mu \mathrm{l} \\
3 \mathrm{mg} / \mathrm{kg}\end{array}$ & $\begin{array}{l}\text { Twice a day } \\
\text { Once a week }\end{array}$ \\
\hline
\end{tabular}

XHW: Xihuang Wan; p.o.: oral gavage; i.p.: intraperitoneal injection.

\section{Materials and Methods}

Preparation of Chinese medicine formula. Xihuang Wan (XHW) was obtained from Tongrentang (Beijing, China; Lot number: 18041283). XHW was dissolved in sodium carboxymethyl cellulose (CMC-Na) solution $(5 \mathrm{mg} / \mathrm{ml} \mathrm{CMC-Na} \mathrm{in} \mathrm{sodium} \mathrm{chloride} \mathrm{for}$ injection) at $0.493 \mathrm{~g} / \mathrm{ml}, 0.246 \mathrm{~g} / \mathrm{ml}$, and $0.123 \mathrm{~g} / \mathrm{ml}$.

Drugs and reagents. Cisplatin was obtained from Qilu Pharmaceutical (Shandong, PR China). CMC-Na was obtained from Solarbio (Beijing, PR China). Pentobarbital sodium salt was obtained from Sigma-Aldrich (St. Louis, MO, USA). Sodium chloride for injection was obtained from Tiancheng Pharmaceutical (Hebei, PR China).

Cancer cell line. The LLC cell line LL/2 (LLC1) was purchased from KeyGEN BioTECH (Jiangsu, China). The cells were maintained in high-glucose DMEM (EallBio, Beijing, PR China) supplemented with $10 \%$ fetal bovine serum (Analysis Quiz, Beijing, PR China), penicillin $(100 \mathrm{U} / \mathrm{ml}$, EallBio) and streptomycin $(100 \mu \mathrm{g} / \mathrm{ml}$, EallBio $)$ at $37^{\circ} \mathrm{C}$ in a $\mathrm{CO}_{2}$ incubator.

Mice. C57BL/6 mice (6-8 weeks, male) were obtained from SPF Biotechnology (Beijing, China, License No. SYXK 2019-0010). The mice were fed with an autoclaved laboratory rodent diet (SPF Biotechnology) and housed in a barrier facility in high efficacy particulate air (HEPA)-filtered racks under standard conditions of 12$\mathrm{h}$ light/dark cycles. The mice were anesthetized by peritoneal injection of pentobarbital sodium at a dose of $50 \mathrm{mg} / \mathrm{kg}$. The response of the mice was monitored to ensure adequate depth of anesthesia. The animals were observed daily and sacrificed by $\mathrm{CO}_{2}$ inhalation if the following humane end point criteria were met: severe tumor burden (over $20 \mathrm{~mm}$ in diameter), significant body weight loss, body temperature drop, difficulty in breathing, prostration and rotational motion. The present study was conducted in accordance with the Guidelines of Welfare and Ethics of Laboratory Animals (IACUC Issue No. AW2020111001) by SPF Biotechnology (36).

Experimental design. Fifty-four mice were randomized into 6 groups: 1) untreated control $(\mathrm{n}=10)$; 2) low-dose XHW $[0.617 \mathrm{~g} / \mathrm{kg}$, oral gavage (p.o.), $\mathrm{n}=10]$; 3) medium-dose XHW (1.233 g/kg, p.o., $\mathrm{n}=10)$; 4) high-dose XHW (2.466 g/kg, p.o., $\mathrm{n}=10)$; and 5) cisplatin
[3 $\mathrm{mg} / \mathrm{kg}$, intraperitoneal injection (i.p.), $\mathrm{n}=10$ ]; and 6) the blank group $(n=4)$. LLC cells $\left(1 \times 10^{6} / 200 \mu \mathrm{l}\right)$ were injected subcutaneously into the right flank of the mice, except for the 4 mice in the blank group $(37,38)$. Treatment was started the next day. Details of the treatment protocol are presented in Table I. The condition of the mice was monitored every day. The body weight and the tumor length and width were measured every 3 days. When the diameter of the tumor reached $20 \mathrm{~mm}$, drug administration was stopped, and the mice were sacrificed. The tumor, spleen, liver, lung and thymus were removed and weighed. The tumor volume was calculated with the following formula: $0.5 *$ Length*Width ${ }^{2}$ (39). The ratios of organ weight to body weight (spleen, liver, lung, and thymus) were calculated to determine whether there was treatment-associated toxicity.

Histological examination and Ki-67 immunohistochemical staining. Freshly-harvested tumors and the livers were fixed in $10 \%$ formalin and embedded in paraffin for further histology analysis. Hematoxylin and eosin (H\&E) staining and immunochemical staining were performed according to standard protocols $(40,41)$. Ki-67 staining was performed with a primary anti-Ki-67 antibody (1:200; Abcam, Cambridge, UK). The Ki-67 index was calculated as the percentage of positively stained cancer cells among all cancer cells. The images were obtained with a Leica Microsystems DM3000 (Leica Camera AG, Wetzlar, Germany) with CIM-2 software without post-acquisition processing.

RNA-sequencing analysis. The freshly removed tumors in the control group and high-dose XHW group were frozen in liquid nitrogen and then sent to the Beijing Genomics Institute (BGI, Shenzhen, PR China) for RNA-sequencing. Three parallel replicates of each sample were analyzed. RNA-sequencing was performed using the DNBSEQ platform (BGI). The data were analyzed on the Dr. Tom II network platform of the BGI (https://biosys.bgi.com/). The sequencing data were filtered with SOAPnuke (v1 .5.2) (42) to remove reads containing sequencing adapter, reads with a low-quality base ratio (base quality less than or equal to 5) of more than $20 \%$, and reads whose unknown base (' $\mathrm{N}$ ' base) ratio was more than $5 \%$. The clean reads were obtained and stored in FASTQ format. The clean reads were mapped to the reference genome using HISAT2 (v2.0.4) (43). Bowtie2 (v2.2.5) (44) was applied to align the clean reads to the reference coding gene set, then the expression levels of the genes were calculated by RSEM (v1.2.12) (45). Essentially, differential expression analysis was 
performed using the DEGseq (v1.44.0) (46) with a Q value $\leq 0.001$. KEGG (https://www.kegg.jp/) enrichment analysis of annotated differentially expressed genes was performed by Phyper (https://en.wikipedia.org/wiki/Hypergeometric_distribution) based on the Hypergeometric test. The significant levels of terms and pathways were corrected by $\mathrm{Q}$ value with a rigorous threshold ( $\mathrm{Q}$ value $\leq 0.05$ ) determined by the Bonferroni analysis (47)

Statistical analysis. All statistical analyses were performed by SPSS Statistics 26 (IBM, New York City, NY, USA). The Shapiro-Wilk test was used to assess the normal distribution. The Bartlett's test was used to verify the homogeneity of variances among groups. One-way ANOVA with LSD for post hoc analysis was used for the parametric test. The Kruskal-Wallis one-way ANOVA with SteelDwass for post hoc analysis was used for the non-parametric comparison. The experimental data are expressed as the mean \pm standard deviation (SD). A $p$-value of 0.05 or less was considered statistically significant.

\section{Results}

Efficacy of treatment on the LLC tumor. XHW inhibited LLC tumor growth to a similar extent as cisplatin in the syngeneic model. Tumor volume in the cisplatin and the high-dose XHW groups were significantly smaller that in the control group ( $p<0.01$ and $p<0.05$ respectively). Tumor weights in the cisplatin and high-dose XHW groups were also significantly smaller than that in the control group $(p<0.01$ and $p<0.05$ respectively) (Figure $1 \mathrm{~A}$ and $\mathrm{B}$ ).

Effect of treatment on body and organ weight. There was no significant change of body weight in any group during the 15day drug administration period. The mice treated with high-dose XHW had the largest livers among the tumor-bearing mice $(p<0.001)$. There was no statistically significant difference in the size of the spleen, lung, and thymus among the different groups (Figure 2A and B).

Effect of treatment on histology. Under light microscopy, LLC cells in the untreated control group were densely arranged with obvious anaplastic characteristics: various cell sizes and diverse morphologies; variable cell nuclei sizes and increased nucleus to cytoplasm ratio; granular chromatin and uneven distribution. Pathological mitoses such as multipolar and asymmetric nuclear divisions were observed. In the cisplatin group, more cells showed morphological changes associated with apoptosis including chromatin aggregation, nuclear consolidation, nuclear fragmentation and lysis. In the high-dose XHW and cisplatin group, necrotic areas were observed (Figure 3 ).

Although the liver index was larger in each group compared to that in the blank group, there was no significant difference in liver histology among all groups. All groups had normal liver parenchyma with unremarkable hepatocytes having vacuolated cytoplasm, bland nuclei, and punctate nucleoli (Figure 4).
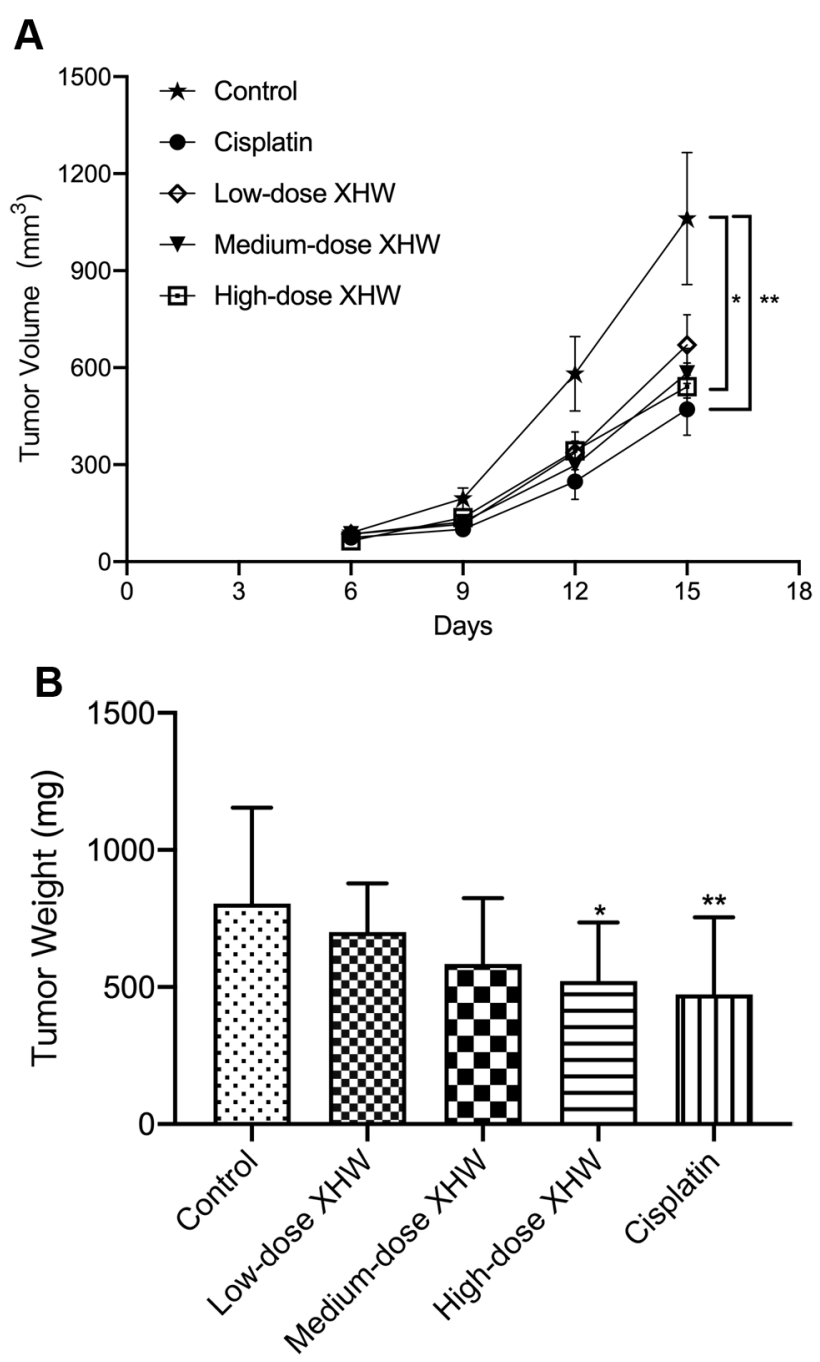

Figure 1. Efficacy of treatment on the Lewis lung carcinoma (LLC). A: Growth curve of tumor volume. B: Efficacy of treatment on the LLC tumor weight. $* p<0.05 ; * * p<0.01$

Effect of treatment on $\mathrm{Ki}-67$ index. The Ki-67 index in the control group was $7.35 \% \pm 0.90 \%$, which was significantly greater than that in the cisplatin group $(1.31 \% \pm 1.04 \%$, $p<0.001)$, the low-dose XHW group $(1.94 \% \pm 0.25 \%$, $p<0.001)$, the medium-dose XHW group $(1.50 \% \pm 0.33 \%$, $p<0.001)$, and the high-dose XHW group $(1.87 \% \pm 0.43 \%$, $p<0.001$ ) (Figure 5).

RNA-sequencing analysis. An average of $23.12 \mathrm{Mb}$ clean reads, with an average genome mapping rate of $96.41 \%$, was obtained. There were 406 differentially expressed genes between the control group and high-dose XHW group ( $\mid \log 2 \mathrm{FCl} \geq 1$, Q value $\leq 0.001), 130$ genes were up-regulated, 276 genes were down-regulated (Figure 6A). The KEGG pathway cluster analysis showed that the 406 genes were 


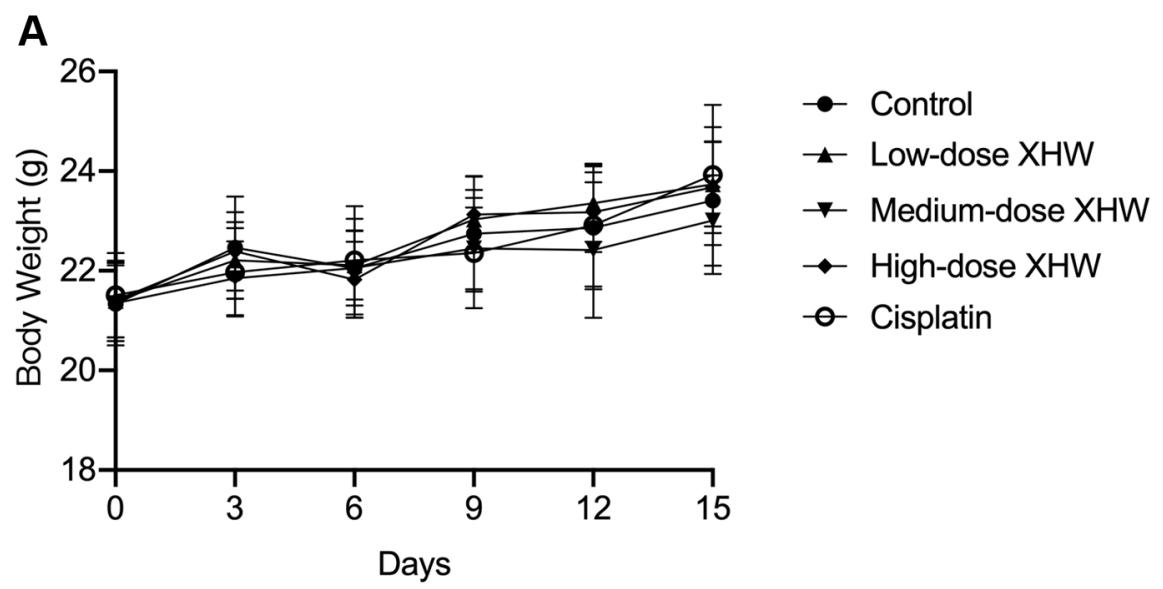

B

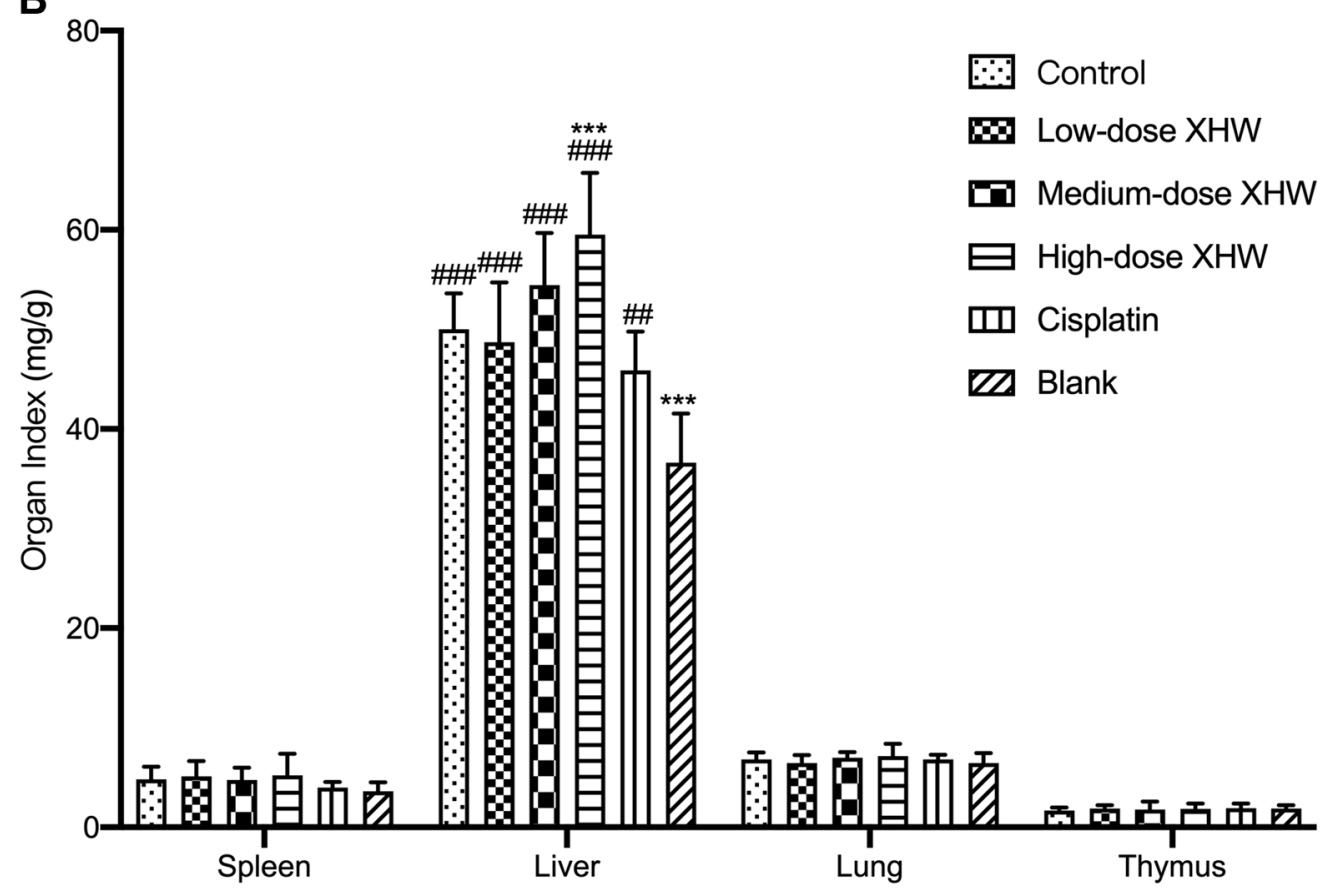

Figure 2. Effect of treatment on body weight and organ weight ratio. A: Body weight. B: Organ ratio (spleen, liver, lung and thymus). ${ }^{*} p<0.05 v s$. control; $\# p<0.01$ vs. blank; \#\# $p<0.001$ vs. blank.

closely associated with multiple signaling pathways, including tumor necrosis factor (TNF), estrogen, cyclic guanosine 3', 5' -monophosphate-protein kinase G (cGMP$\mathrm{PKG})$, apelin and the peroxisome proliferator-activated receptor (PPAR) signaling pathways (Figure 6B).

\section{Discussion}

The present study showed that XHW inhibited the growth of LLC in a syngeneic mouse model, and reduced the Ki-67 index, indicating that XHW alone could inhibit lung cancer.
XHW alone was at least as effective as the first-line cytotoxic drug cisplatin both on tumor growth inhibition and decrease in the Ki-67 index. No toxicity was observed in histology among all groups. Thus, XHW is a candidate to replace cisplatin in lung cancer treatment. This may become very important clinically since many patients cannot tolerate platinum-based drugs.

A previous study on XHW treatment of LLC cells indicated that 11 metabolites were differentially expressed compared to the untreated control, including L-phenylalanine, L-tryptophan, farnesylcysteine, LysoPC(18:1(9Z)/0:0, L-adrenaline, 4- 

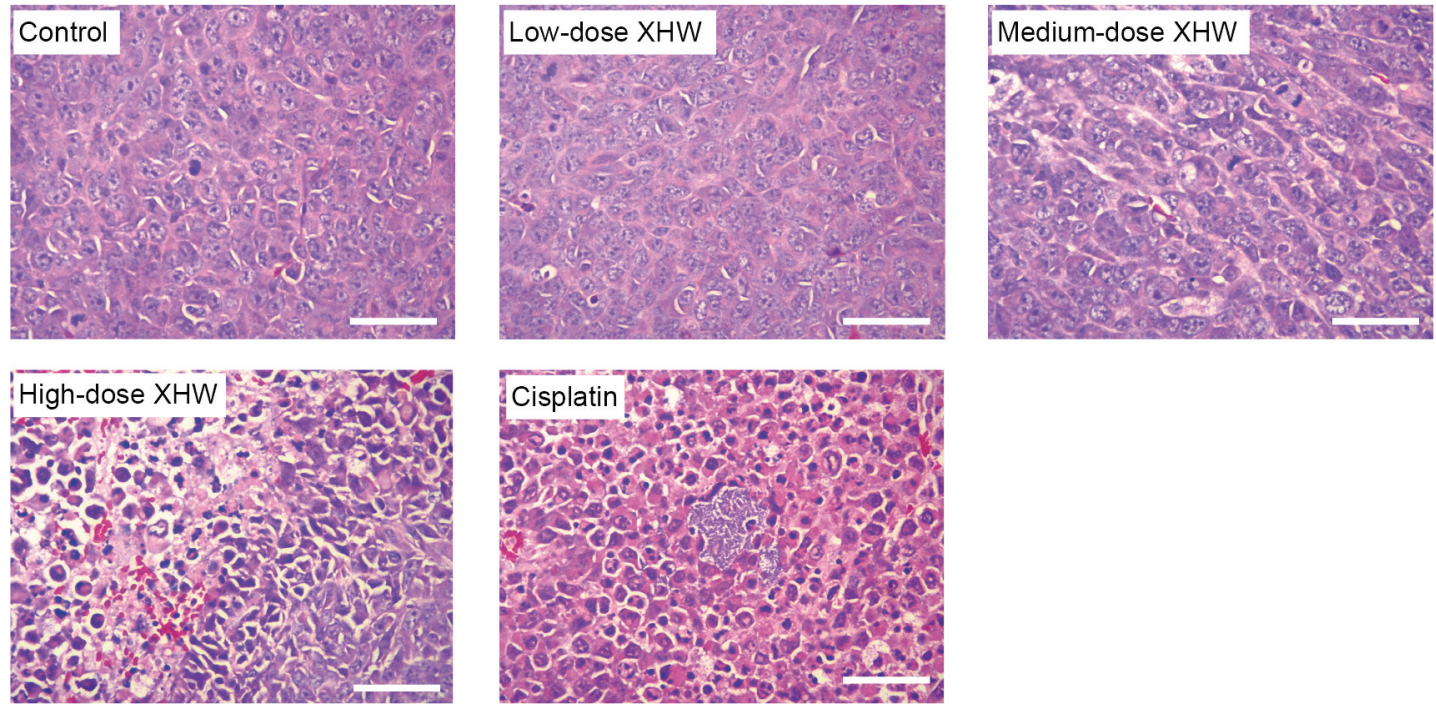

Figure 3. Effect of treatment on tumor histology. Hematoxylin and eosin staining was performed according to standard protocols. Under light microscopy, LLC cells in the untreated control group were densely arranged with obvious anaplastic characteristics: various cell sizes and diverse morphologies; variable cell nuclei sizes and increased nucleus to cytoplasm ratio; granular chromatin and uneven distribution. Pathological mitoses such as multipolar and asymmetric nuclear divisions were observed. In the cisplatin group, more cells showed morphological changes associated with apoptosis including chromatin aggregation, nuclear consolidation, nuclear fragmentation and lysis. In the high-dose XHW and cisplatin group, necrotic areas were observed. Scale bar: $50 \mu \mathrm{m}$.
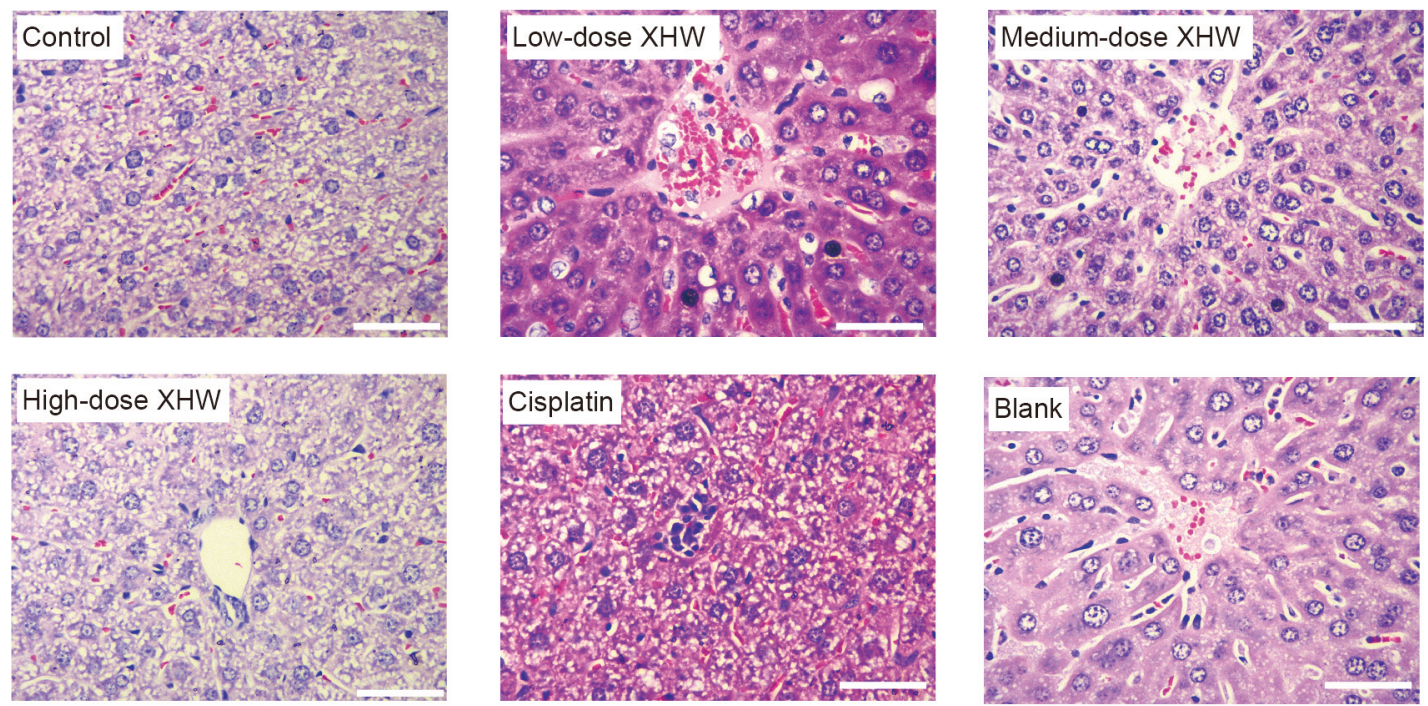

Figure 4. Effect of treatment on liver histology. Freshly-harvested livers were fixed in $10 \%$ formalin and embedded in paraffin and stained with hematoxylin and eosin. All groups had normal liver parenchyma with unremarkable hepatocytes having vacuolated cytoplasm, bland nuclei, and punctate nucleoli. There was no significant difference in liver histology among all groups. Scale bar: 50 um.

maleylacetoacetate, guanosine, aminoimidazole ribotide, corticosterone, sphingosine-1-phosphate and D-urobilinogen (48), suggesting that XHW plays a major role in altering aromatic amino-acid metabolism in the LLC mouse model.
Previous studies showed that XHW induced apoptosis of human glioblastoma U-87 MG cells via targeting the ROSactivated Akt/mTOR/FOXO1 pathway (49), and potentiated the efficacy of temozolomide on a glioblastoma xenograft 

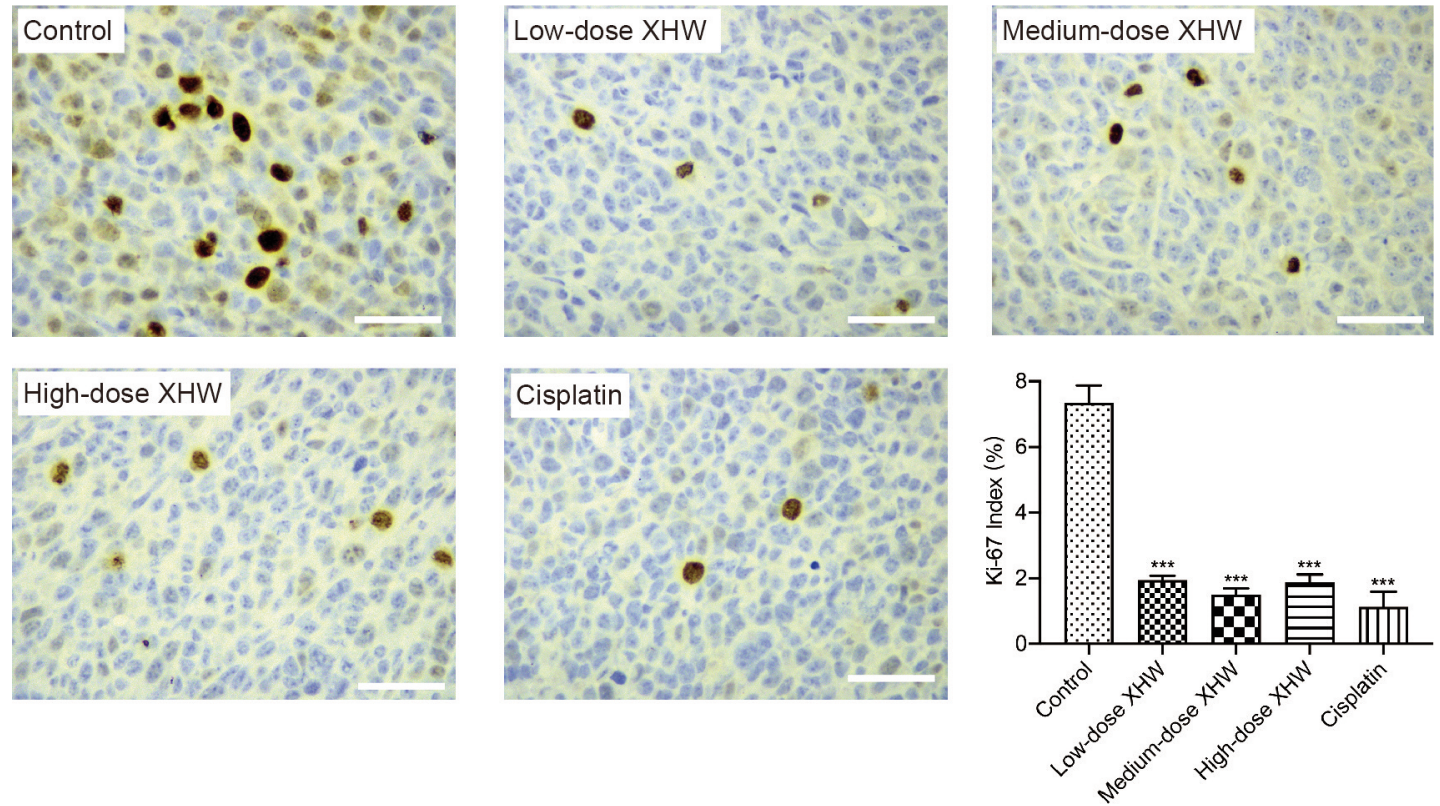

Figure 5. Effect of treatment on the Ki-67 index. Ki-67 staining was performed with a primary anti-Ki-67 antibody. The Ki-67 index was calculated as the percentage of positively stained cancer cells among all cancer cells. The Ki-67 index in the control group was significantly greater than that in the cisplatin, the low-dose XHW, the medium-dose XHW, and the high-dose XHW group.

through the Akt/mTOR pathway (50). XHW has also been shown to promote apoptosis of Treg cells in the tumor microenvironment in a $4 \mathrm{~T} 1$ breast-cancer mouse model by upregulating the MEKK1/SEK1/JNK1/AP-1 pathway (51). A systems pharmacology and proteomics study of XHW on triple-negative breast cancer (TNBC) showed that XHW may be effective on non-small cell lung cancer and small cell lung cancer, as demonstrated by the KEGG signaling pathway enrichment analysis (52).

In the present study, to further explore the mechanism of XHW inhibition of LLC in a syngeneic mouse model, RNAsequencing (RNA-seq) was performed. RNA-seq demonstrated that many signaling pathways were involved, including TNF, estrogen, cGMP-PKG, apelin and PPAR signaling pathways. A previous transcriptomics and chemical informatics study showed that the TNF and estrogen signaling pathways were also involved in XHW-mediated inhibition of TNBC (53). Estrogen and the estrogen receptor have the potential to become prognosticators and therapeutic targets in lung cancer (54). Another previous study examining the effect of XHW on multiple cancers by network pharmacology showed that one of the key targets of XHW is estrogen receptor 1 (ESR1) (55). The TNF signaling pathway is involved in many physiological and pathological processes, including cell proliferation, apoptosis, regulation of immune responses and inflammation (56), closely related to cancer, including lung cancer (57). Apelin, a transmembrane $\mathrm{G}$ protein-coupled receptor, is an endogenous ligand of the apelin receptor, and is upregulated in multiple cancer types including lung cancer, colon cancer, gastroesophageal cancer, hepatocellular carcinoma and brain cancer (58). Down-regulation of apelin has been shown to inhibit mammary and lung cancer growth as well as lung metastasis (59). PPARs are nuclear hormone receptors activated by fatty acids and their derivatives, PPAR $\gamma$ is expressed in various cancer types including lung cancer. Reduced PPAR $\gamma$ and elevated cyclooxygenase-2 (COX-2) expression are associated with poor prognosis in lung cancer patients. PPAR $\gamma$ is considered to be a therapeutic target for lung cancer (60-62). Cyclic GMP (cGMP) is an intracellular second messenger, mediating the action of nitric oxide (NO) and natriuretic peptides (NPs). cGMP has been shown to exert its physiological action through cGMP-dependent protein kinase (PKG), cGMP-regulated phosphodiesterases (PDE2, PDE3) and cGMP-gated cation channels. The cGMP-PKG pathway has been found to be closely related to lung cancer $(63,64)$.

The RNA-seq results and KEGG pathway enrichment analysis of the present study showed that many signaling pathways were altered following treatment of the syngeneic LLC mouse model with XHW, indicating that XHW inhibited the LLC carcinoma through many different pathways. These pathways need to be further studied, including their interaction, to develop an improved therapy for lung cancer. 


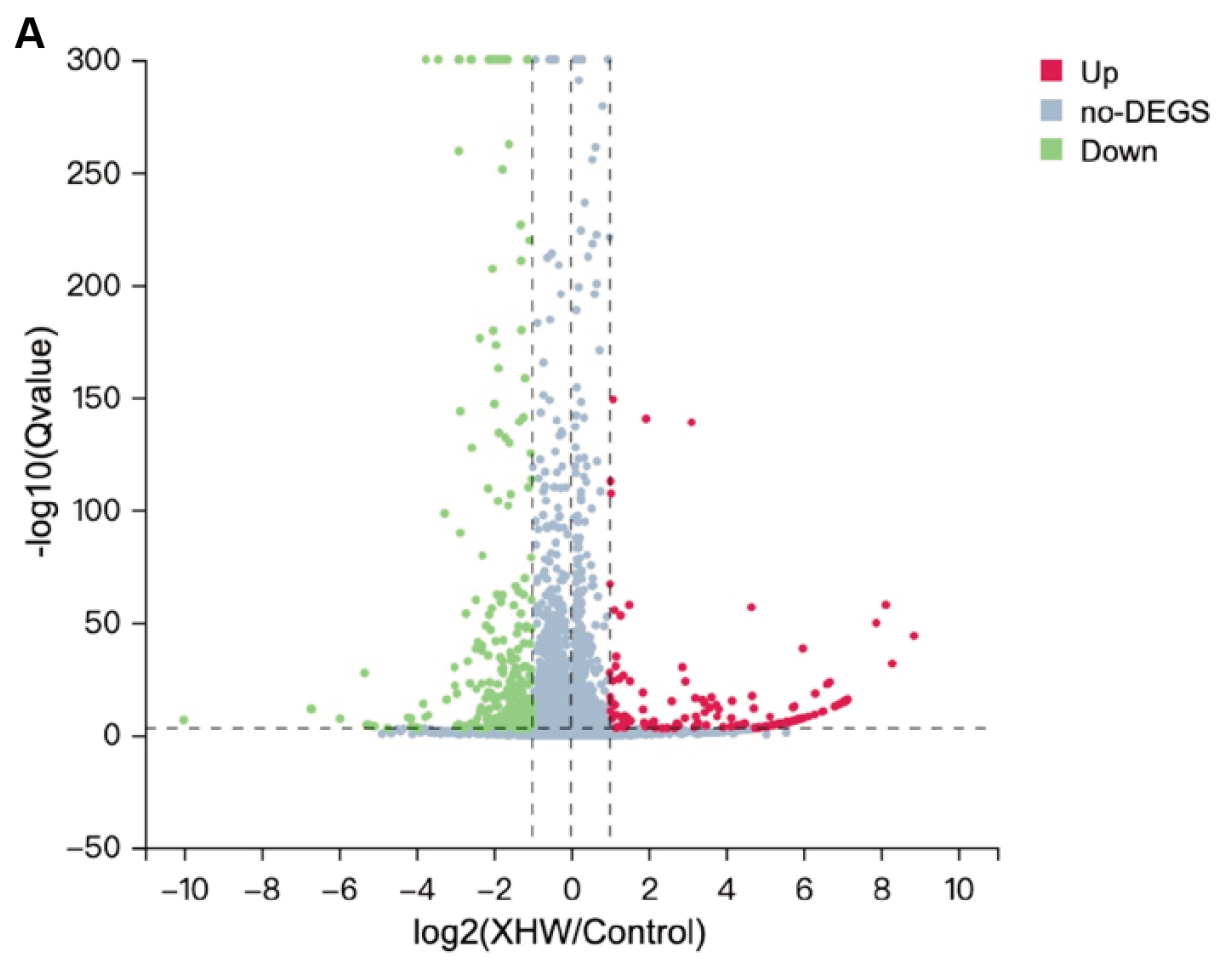

B

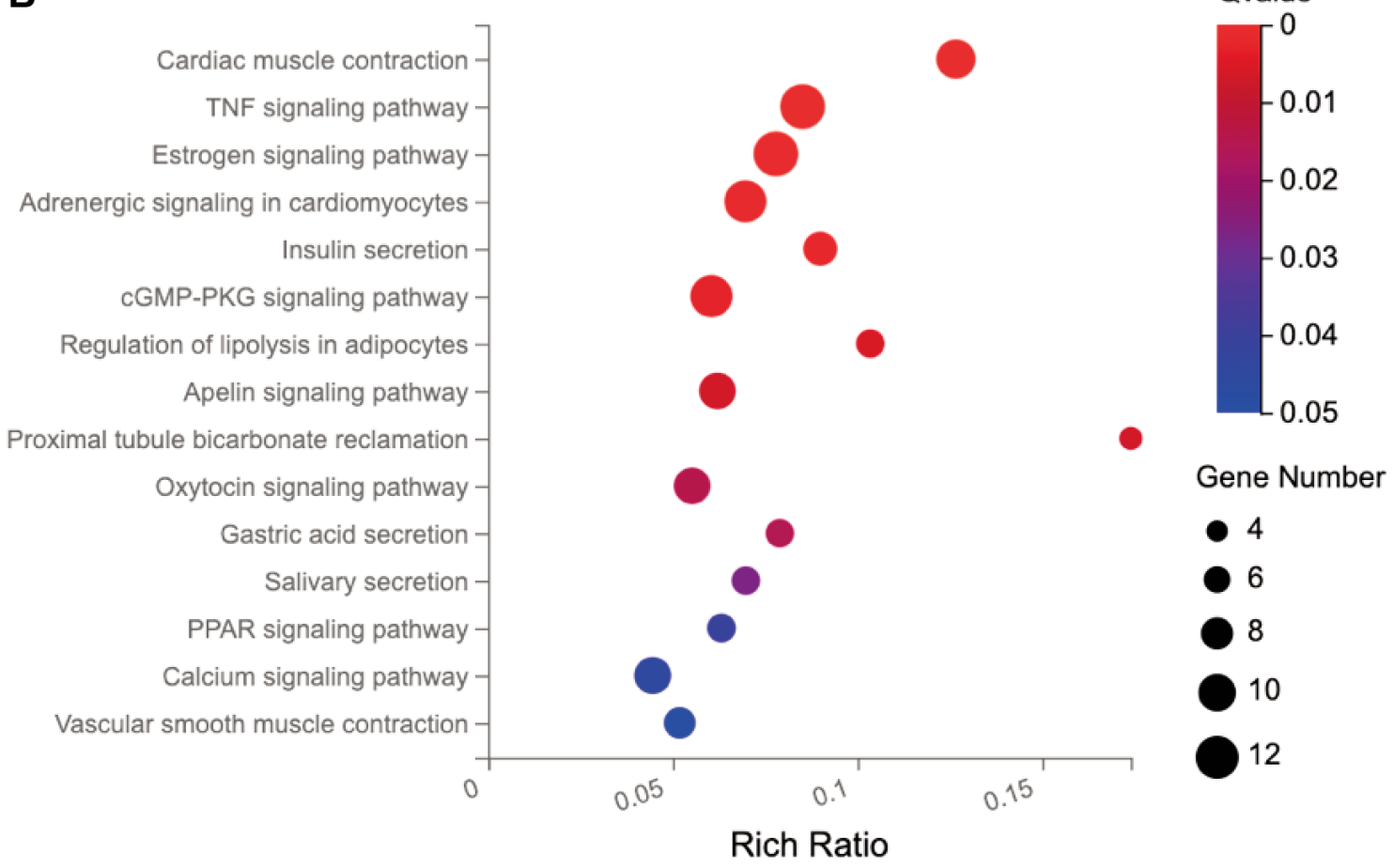

Figure 6. Effect of high-dose XHW on gene expression. A) Volcano map of differentially expressed genes between the control group and the highdose XHW group. There were 406 differentially expressed genes ( $\mid \log 2 F C l \geq 1, Q$ value $\leq 0.01), 130$ genes were up-regulated, 276 genes were downregulated. B) KEGG pathway cluster analysis based on the 406 genes was significantly changed as described in A. 


\section{Conflicts of Interest}

All the Authors declare no conflicts of interest in relation to this study.

\section{Authors' Contributions}

$\mathrm{ZZ}$ and ZT designed the study. ZZ, WJ, DH, LD, ZX, PH and SM performed the experiments. $\mathrm{ZZ}$ and $\mathrm{LX}$ analyzed the data. $\mathrm{ZZ}$ and $\mathrm{ZX}$ drafted the article. RMH revised the article and rewrote the Discussion. HK administrated and supervised the study.

\section{Acknowledgements}

This study was supported by Horizontal Scientific Research Project of Dongfang Hospital, Beijing University of Chinese Medicine (No. 040101003063).

\section{References}

1 Sung H, Ferlay J, Siegel RL, Laversanne M, Soerjomataram I, Jemal A and Bray F: Global Cancer Statistics 2020: GLOBOCAN estimates of incidence and mortality worldwide for 36 cancers in 185 countries. CA Cancer J Clin 71(3): 209249, 2021. PMID: 33538338. DOI: 10.3322/caac.21660

2 Ferlay J, Ervik M, Lam F, Colombet M, Mery L, Piñeros M, Znaor A, Soerjomataram I and Bray F: Global Cancer Observatory: Cancer Today. Available at: http://gco.iarc.fr/today [Last accessed on February 19, 2021]

3 National Comprehensive Cancer Network: Non-small cell lung cancer (Version 3.2021). Available at: https://www.nccn.org/ professionals/physician_gls/pdf/nscl.pdf [Last accessed on February 23, 2021]

4 National Comprehensive Cancer Network: Small cell lung cancer (Version 2.2021). Available at: https://www.nccn.org/ professionals/physician_gls/pdf/sclc.pdf [Last accessed on February 23, 2021]

$5 \mathrm{He}$ J, Yin P and Xu K: Effect and molecular mechanisms of traditional Chinese medicine on tumor targeting tumorassociated macrophages. Drug Des Devel Ther 14: 907-919, 2020. PMID: 32184560. DOI: 10.2147/DDDT.S223646

6 Xiang Y, Guo Z, Zhu P, Chen J and Huang Y: Traditional Chinese medicine as a cancer treatment: Modern perspectives of ancient but advanced science. Cancer Med 8(5): 1958-1975, 2019. PMID: 30945475. DOI: $10.1002 /$ cam4.2108

7 Luo H, Vong CT, Chen H, Gao Y, Lyu P, Qiu L, Zhao M, Liu Q, Cheng Z, Zou J, Yao P, Gao C, Wei J, Ung COL, Wang S, Zhong $\mathrm{Z}$ and Wang Y: Naturally occurring anti-cancer compounds: shining from Chinese herbal medicine. Chin Med 14: 48, 2019. PMID: 31719837. DOI: 10.1186/s13020-019-0270-9

8 Ling CQ, Yue XQ and Ling C: Three advantages of using traditional Chinese medicine to prevent and treat tumor. J Integr Med 12(4): 331-335, 2014. PMID: 25074882. DOI: 10.1016/ S2095-4964(14)60038-8

9 Xu W, Ding S, Xu ningning, Shi L and Qi B: Therapeutic effects of Xihuang Pills combined with GP chemotherapy on advanced breast cancer. Hebei Med J 42: 1358-1361, 2020 (in Chinese). Available at: https://chn.oversea.cnki.net/KCMS/detail/detail. asp $x$ dbcode $=$ CJFD $\&$ dbname $=$ CJFDLAST2020 $\&$ filename $=H B$
YZ202009018\&v=2JUXz59LHYVOrG0SqVe\%25mmd2BQq $\% 2$ 5mmd2BkeCleRUf951PhusEzMOmrPTo5perCDUhGm\%25mmd 2F\%25mmd2FRtxM4 [Last accessed on May 31, 2021]

$10 \mathrm{Wu}$ J and Wang D: Clinical study on xihuang capsules combined with TEC chemotherapy scheme for breast cancer of stage III and its effect on immune function. J N Chin Med 52: 117-119, 2020. DOI: $10.13457 /$ j.cnki.jncm.2020.12.035

11 Qian W, Li Z, Li R, Zhao Y, Xiao H, Si H, Chen X, Fang Y and $\mathrm{Wu} Z$ : Effect of xihuang pill combined with TP regimen in treatment of advanced breast cancer. Liaoning J Traditional Chin Med 47: 115-117, 2020 (in Chinese). Available at: https://chn.oversea.cnki.net/KCMS/detail/detail.aspx?dbcode=CJ FD $\&$ dbname $=$ CJFDLAST2020 $\&$ filename $=$ LNZY202006038 \&v =VIkb2pgOmHDvOn6LToVyb8wR8JmTdopTf5wPsNJKn9\%25 mmd2Bv9\%25mmd2F7eeJgt1M\%25mmd2BBZhP8e\%25mmd2 Bvp [Last accessed on May 31, 2021]

12 Jin J and Li Z: Integrated Xihuang Pills and chemotherapy in treating 30 patients with breast cancer. Chin J Traditional Chin Med Pharm 25: 715-716, 2010 (in Chinese). Available at: https://chn.oversea.cnki.net/KCMS/detail/detail.aspx?dbcode=CJ $\mathrm{FD} \&$ dbname $=\mathrm{CJFD} 2010 \&$ filename $=\mathrm{BXYY} 201005027 \& \mathrm{v}=\mathrm{CvO}$ M3FgCJkQBycg4\%25mmd2BfC0CAaUNi2APi1G0oFuMOQ7p Er7r37cLhcblgVC6ycAURIM [Last accessed on May 31, 2021]

13 Yu D and An GY: Clinical effects of Xihuang pill combined with chemotherapy in patients with advanced colorectal cancer. Evid Based Complement Alternat Med 2017: 5936086, 2017. PMID: 28458715. DOI: $10.1155 / 2017 / 5936086$

14 Zhou Y: Effect of xihuang pills in adjuvant treatment of advanced primary liver cancer. Chin J Clin Ration Drug Use 13: 73-75, 2020 (in Chinese). Available at: https://chn.oversea. cnki.net/KCMS/detail/detail. aspx $?$ dbcode $=$ CJFD $\&$ dbname $=$ CJF DLAST2020\&filename $=$ PLHY202004041 \&v $=$ jhCilz52XxzJ8D8 IJM63eS\%25mmd2B9tMunWHppZosGFrrnCS\%25mmd2BnAs h4Bkqt94qLk1hkSO1f [Last accessed on May 31, 2021]

15 Liu B, Yu S, Xing L, Zhao X, Lv Y and Gao Q: Analysis of therapeutical effects of Xihuang Pills with intraarterial intervention chemotherapy on 80 cases of advanced primary hepatic carcinoma. China J Traditional Chin Med Pharm 25: 947-948, 2010 (in Chinese). Available at: https:// chn.oversea.cnki.net/KCMS/detail/detail.aspx ?dbcode=CJFD \&d bname $=\mathrm{CJFD} 2010 \&$ filename $=\mathrm{BXYY} 201006050 \& \mathrm{v}=\mathrm{CvOM} 3 \mathrm{Fg}$ CJkRcWaomMUz6GDZ7riVXwU6bcrgodk7DcyjkUBxYsNXeL QhTKWcR4jMB [Last accessed on May 31, 2021]

16 Zhang G: Analysis of the effect of xihuangwan combined with TP chemotherapy on advanced cervical cancer. China Foreign Med Treat 39: 11-14, 2020 (in Chinese). Available at: https://chn.oversea. cnki.net/KCMS/detail/detail .aspx ?dbcode=CJFD \&dbname=CJFDA UTO\&filename $=$ HZZZ202019004\&v=wQoMT\% 25mmd2BEVQT $\% 25 \mathrm{mmd} 2 \mathrm{FOnHhWycRwx} 4 \mathrm{UBgK} 81$ AdQIIWTikRTzizGNqYbwt5 $\% 25$ mmd2FPxkaIjgSxcLBW [Last accessed on May 31, 2021]

17 Shao X: Effects of Xihuang Pill combined with neoadjuvant chemotherapy on the prognosis and Th1/Th2 cytokines in patients with advanced cervical cancer. Chin J Ration Drug Use 17: 92-96, 2020 (in Chinese). Available at: (https://chn.oversea.cnki.net/ $\mathrm{KCMS} /$ detail/detail.aspx ?dbcode=CJFD\&dbname=CJFDLAST202 0\&filename $=$ ZYYS202006022 \&v=d7lumuE8ajmOqxuiesLm $\% 25 \mathrm{~m}$ md2BkAPfjgjJmE2j\%25mmd2BRwj9KN0bQrZGGes\%25mmd2Fl ZTShL0eM2xvHL [Last accessed on May 31, 2021]

$18 \mathrm{Li} \mathrm{L}$ and $\mathrm{Ke} \mathrm{X}$ : Effect of Xihuang Capsule combined with radiotherapy on 45 cases of cervical cancer. Acta Chin Med 
Pharmacol 37: 78-79, 2009 (in Chinese). Available at: https://chn.oversea.cnki.net/KCMS/detail/detail.aspx?dbcode $=\mathrm{CJ}$ FD $\&$ dbname $=$ CJFD2009 \& filename $=\mathrm{ZYXB} 200904035 \& \mathrm{v}=\mathrm{W} \% 2$ 5mmd2BUQAkAI\%25mmd2Fvl\%25mmd2BOwGLZCsizGLJq1 14RW\%25mmd2FNI6wtCLn7xiihP\%25mmd2FSkogCh5bVS87 bflquA [Last accessed on May 31, 2021]

19 He S, Gao Y, Jin X, Wang Y, Zhang F and Liu B: Effect of vinorelbine+cisplatin chemotherapy combined with Xihuang Pills in the treatment of lung squamous cell carcinoma. Clin J Med Officers 48: 305-306, 2020 (in Chinese). Available at: (https://chn.oversea.cnki.net/KCMS/detail/detail.aspx?dbcode=CJF D\&dbname $=$ CJFDLAST2020\&filename $=J Y G Z 202003022 \& v=\mathrm{sS}$ mQnTLRqPYyS9rSwJK2MFaXtGy5YfOC50CgA5FFYCgN5EU6 uJSOLZW9224\%25mmd2BJqsV [Last accessed on May 31, 2021]

20 Chen Y: Efficacy and safety of Xihuang Capsule combined with chemotherapy in the treatment of advanced lung adenocarcinoma. Med Diet Health 18: 12-13, 2020 (in Chinese). Available at: https://chn.oversea.cnki.net/KCMS/detail/detail. asp $\mathrm{P}$ dbcode $=$ CJFD $\&$ dbname $=$ CJFDLAST2020\&filename $=$ YXS L202011008\&v=K2j\%25mmd2BVjy9XFnGA1VpHW41mniwx xrnx5ShQ\%25mmd2FqFUy9U6FhflPsa6409UExLjVenQsE1 [Last accessed on May 31, 2021]

$21 \mathrm{Cen} \mathrm{H}$ : Clinical trial of Xihuang pill combined with irinotecan and cisplatin chemotherapy in the treatment of limited stage small cell lung cancer. Chin J Clin Pharmacol 33: 1307-1310, 2017 (in Chinese). Available at: https://chn.oversea.cnki.net/KCMS/detail/ detail aspx ?dbcode $=$ CJFD \&dbname $=$ CJFDLAST2017\&filename $=$ GLYZ201714006\&v=PovXhSV\%25mmd2B2SK4wFw54rxsd9nD L0sZjpO77KYdYCkRzw92wNnIoOgG17JuLz5utNRA [Last accessed on May 31, 2021]

22 Guo Q, Xu X, He S, Yuan Y, Chen S and Hua B: Xi huang pills enhance the tumor treatment efficacy when combined with chemotherapy: A meta-analysis and systematic review. J Cancer Res Ther 14(Suppl): S1012-S1018, 2018. PMID: 30539838. DOI: $10.4103 / 0973-1482.192795$

23 Yang M, Jiang P and Hoffman RM: Whole-body subcellular multicolor imaging of tumor-host interaction and drug response in real time. Cancer Res 67(11): 5195-5200, 2007. PMID: 17545599. DOI: 10.1158/0008-5472.CAN-06-4590

24 Zhang Y, Zhang N, Zhao M and Hoffman RM: Comparison of the selective targeting efficacy of Salmonella typhimurium A1$\mathrm{R}$ and VNP20009 on the Lewis lung carcinoma in nude mice. Oncotarget 6(16): 14625-14631, 2015. PMID: 25714030. DOI: 10.18632/oncotarget. 3342

25 Yoshioka T, Wada T, Uchida N, Maki H, Yoshida H, Ide N, Kasai H, Hojo K, Shono K, Maekawa R, Yagi S, Hoffman RM and Sugita K: Anticancer efficacy in vivo and in vitro, synergy with 5-fluorouracil, and safety of recombinant methioninase. Cancer Res 58(12): 2583-2587, 1998. PMID: 9635582.

26 Yang M, Baranov E, Li XM, Wang JW, Jiang P, Li L, Moossa AR, Penman S and Hoffman RM: Whole-body and intravital optical imaging of angiogenesis in orthotopically implanted tumors. Proc Natl Acad Sci USA 98(5): 2616-2621, 2001. PMID: 11226288. DOI: 10.1073/pnas.051626698

27 Liu F, Zhang L, Hoffman RM and Zhao M: Vessel destruction by tumor-targeting Salmonella typhimurium A1-R is enhanced by high tumor vascularity. Cell Cycle 9(22): 4518-4524, 2010. PMID: 21135579. DOI: $10.4161 / \mathrm{cc} .9 .22 .13744$

28 Zhao M, Suetsugu A, Ma H, Zhang L, Liu F, Zhang Y, Tran B and Hoffman RM: Efficacy against lung metastasis with a tumor-targeting mutant of Salmonella typhimurium in immunocompetent mice. Cell Cycle 11(1): 187-193, 2012. PMID: 22186786. DOI: 10.4161/cc.11.1.18667

29 Uchugonova A, Zhao M, Zhang Y, Weinigel M, König K and Hoffman RM: Cancer-cell killing by engineered Salmonella imaged by multiphoton tomography in live mice. Anticancer Res 32(10): 4331-4337, 2012. PMID: 23060555.

30 Li L, Wang M, Yu G, Chen P, Li H, Wei D, Zhu J, Xie L, Jia H, Shi J, Li C, Yao W, Wang Y, Gao Q, Jeong LS, Lee HW, Yu J, Hu F, Mei J, Wang P, Chu Y, Qi H, Yang M, Dong Z, Sun Y, Hoffman RM and Jia L: Overactivated neddylation pathway as a therapeutic target in lung cancer. J Natl Cancer Inst 106(6): dju083, 2014. PMID: 24853380. DOI: 10.1093/jnci/dju083

31 Yang M, Baranov E, Wang JW, Jiang P, Wang X, Sun FX, Bouvet M, Moossa AR, Penman S and Hoffman RM: Direct external imaging of nascent cancer, tumor progression, angiogenesis, and metastasis on internal organs in the fluorescent orthotopic model. Proc Natl Acad Sci USA 99(6): 3824-3829, 2002. PMID: 11891294. DOI: 10.1073/pnas.052029099

32 Zhou L, Jiang Y, Liu X, Li L, Yang X, Dong C, Liu X, Lin Y, Li Y, Yu J, He R, Huang S, Liu G, Zhang Y, Jeong LS, Hoffman $\mathrm{RM}$ and Jia L: Promotion of tumor-associated macrophages infiltration by elevated neddylation pathway via NF- $x$ B-CCL2 signaling in lung cancer. Oncogene 38(29): 5792-5804, 2019. PMID: 31243299. DOI: 10.1038/s41388-019-0840-4

33 Pilch J, Brown DM, Komatsu M, Järvinen TA, Yang M, Peters D, Hoffman RM and Ruoslahti E: Peptides selected for binding to clotted plasma accumulate in tumor stroma and wounds. Proc Natl Acad Sci USA 103(8): 2800-2804, 2006. PMID: 16476999. DOI: $10.1073 /$ pnas.0511219103

34 Momiyama M, Suetsugu A, Kimura H, Kishimoto H, Aki R, Yamada A, Sakurada H, Chishima T, Bouvet M, Endo I and Hoffman RM: Imaging the efficacy of UVC irradiation on superficial brain tumors and metastasis in live mice at the subcellular level. J Cell Biochem 114(2): 428-434, 2013. PMID: 22961687. DOI: $10.1002 /$ jcb. 24381

35 Jiang Y, Liang Y, Li L, Zhou L, Cheng W, Yang X, Yang X, Qi H, Yu J, Jeong LS, Hoffman RM, Zheng P and Jia L: Targeting neddylation inhibits intravascular survival and extravasation of cancer cells to prevent lung-cancer metastasis. Cell Biol Toxicol 35(3): 233245, 2019. PMID: 31140025. DOI: 10.1007/s10565-019-09472-w

36 MacArthur Clark JA and Sun D: Guidelines for the ethical review of laboratory animal welfare People's Republic of China National Standard GB/T 35892-2018 [Issued 6 February 2018 Effective from 1 September 2018]. Animal Model Exp Med 3(1): 103-113, 2020. PMID: 32318667. DOI: 10.1002/ame2.12111

37 Huang J, Huang X, Chen Z, Zheng Q and Sun R: Dose conversion among different animals and healthy volunteers in pharmacological study. Chin J Clin Pharmacol Therap 1069-1072, 2004. Available at: https://chn.oversea.cnki.net/KCMS/detail/detail.aspx?dbcode=CJFD $\&$ dbname $=$ CJFD2004\&filename $=$ YLZL200409025\&v=8JbFNEeC3 Akj5OoHiiwbr2siTNZH0gVXTEk5G6m38RILVKXJwOEsewcn5 WleKw02 [Last accessed on May 31, 2021]

38 van Moorsel CJ, Pinedo HM, Veerman G, Vermorken JB, Postmus PE and Peters GJ: Scheduling of gemcitabine and cisplatin in Lewis lung tumour bearing mice. Eur J Cancer 35(5): 808-814, 1999. PMID: 10505043. DOI: 10.1016/s0959-8049(99)00004-0

39 Zhang Z, Hu K, Kiyuna T, Miyake K, Kawaguchi K, Igarashi K, Nelson SD, Li Y, Singh SR and Hoffman RM: A patient-derived orthotopic xenograft (PDOX) nude-mouse model precisely 
identifies effective and ineffective therapies for recurrent leiomyosarcoma. Pharmacol Res 142: 169-175, 2019. PMID: 30807865. DOI: 10.1016/j.phrs.2019.02.021

40 Cardiff RD, Miller CH and Munn RJ: Manual hematoxylin and eosin staining of mouse tissue sections. Cold Spring Harb Protoc 2014(6): 655-658, 2014. PMID: 24890205. DOI: 10.1101/pdb. prot073411 ID: 28849123. DOI: $10.3892 / \mathrm{mmr} .2017 .7290$

$41 \mathrm{Kim}$ SW, Roh J and Park CS: Immunohistochemistry for pathologists: Protocols, pitfalls, and tips. J Pathol Transl Med 50(6): 411-418, 2016. PMID: 27809448. DOI: 10.4132/jptm.2016.08.08

42 Li R, Li Y, Kristiansen K and Wang J: SOAP: short oligonucleotide alignment program. Bioinformatics 24(5): 713-714, 2008. PMID: 18227114. DOI: 10.1093/bioinformatics/btn025

43 Kim D, Langmead B and Salzberg SL: HISAT: a fast spliced aligner with low memory requirements. Nat Methods 12(4): 357360, 2015. PMID: 25751142. DOI: 10.1038/nmeth.3317

44 Langmead B and Salzberg SL: Fast gapped-read alignment with Bowtie 2. Nat Methods 9(4): 357-359, 2012. PMID: 22388286. DOI: $10.1038 /$ nmeth. 1923

45 Li B and Dewey CN: RSEM: accurate transcript quantification from RNA-Seq data with or without a reference genome. BMC Bioinformatics 12: 323, 2011. PMID: 21816040. DOI: 10.1186/ 1471-2105-12-323

46 Wang L, Feng Z, Wang X, Wang X and Zhang X: DEGseq: an $\mathrm{R}$ package for identifying differentially expressed genes from RNA-seq data. Bioinformatics 26(1): 136-138, 2010. PMID: 19855105. DOI: 10.1093/bioinformatics/btp612

47 Abdi H: The Bonferonni and Šidák corrections for multiple comparisons. In: Encyclopedia of measurement and statistics. N Salkind (eds.). Thousand Oaks, CA, USA, Sage, 2007.

48 Li C, Chen W, Zhang M, Zhang C, Cao B, Dong B, Qi S, Zhang Y, Fei X, Li X, Li R, Wang J and Li G: Modulatory effects of Xihuang Pill on lung cancer treatment by an integrative approach. Biomed Pharmacother 130: 110533, 2020. PMID: 32739739. DOI: 10.1016/j.biopha.2020.110533

49 Shao M, He Z, Yin Z, Ma P, Xiao Q, Song Y, Huang Z, Ma Y, Qiu Y, Zhao A, Zhou T and Wang Q: Xihuang pill induces apoptosis of human glioblastoma U-87 MG cells via targeting ROS-mediated Akt/mTOR/FOXO1 pathway. Evid Based Complement Alternat Med 2018: 6049498, 2018. PMID: 30046342. DOI: $10.1155 / 2018 / 6049498$

$50 \mathrm{Fu}$ J, Zhu SH, Xu HB, Xu YQ, Wang X, Wang J and Kong PS: Xihuang pill potentiates the anti-tumor effects of temozolomide in glioblastoma xenografts through the Akt/mTOR-dependent pathway. J Ethnopharmacol 261: 113071, 2020. PMID: 32603676. DOI: $10.1016 /$ j.jep.2020.113071

51 Su L, Jiang Y, Xu Y, Li X, Gao W, Xu C, Zeng C, Song J, Weng $\mathrm{W}$ and Liang W: Xihuang pill promotes apoptosis of Treg cells in the tumor microenvironment in $4 \mathrm{~T} 1$ mouse breast cancer by upregulating MEKK1/SEK1/JNK1/AP-1 pathway. Biomed Pharmacother 102: 1111-1119, 2018. PMID: 29710529. DOI: 10.1016/j.biopha.2018.03.063

$52 \mathrm{Xu} \mathrm{X,} \mathrm{Zhang} \mathrm{J,} \mathrm{Zhang} \mathrm{Z,} \mathrm{Wang} \mathrm{M,} \mathrm{Liu} \mathrm{Y} \mathrm{and} \mathrm{Li} \mathrm{X:} \mathrm{Systems}$ pharmacology in combination with proteomics reveals underlying mechanisms of Xihuang pill against triple-negative breast cancer. Bioengineered 11(1): 1170-1188, 2020. PMID: 33092442. DOI: 10.1080/21655979.2020.1834726

53 Yang K, Zeng L, Ge A, Bao T, Xu T, Xie X and Liu L: Exploring the regulation mechanism of Xihuang pill, Olibanum and $\beta$-Boswellic acid on the biomolecular network of triple- negative breast cancer based on transcriptomics and chemical informatics methodology. Front Pharmacol 11: 825, 2020. PMID: 32595497. DOI: 10.3389/fphar.2020.00825

54 Hsu LH, Chu NM and Kao SH: Estrogen, estrogen receptor and lung cancer. Int J Mol Sci 18(8): 1713, 2017. PMID: 28783064. DOI: $10.3390 /$ ijms 18081713

55 Zhuang Z, Wang Y, Zhu R, Lin T, Zhang Y, Xie J and Liu Z: Exploring mechanisms of Xihuang Pill for anti-cancer based on network pharmacology. Traditional Chin Drug Res Clin Pharmacol 31: 823-831, 2020. Available at: https://chn. oversea.cnki.net/KCMS/detail/detail.aspx ?dbcode=CJFD \&dbna me $=$ CJFDLAST2020 $\&$ filename $=Z Y X Y 202007013 \& v=F e K r V X$ SDumGEQ\% 25mmd2FemMXp\%25mmd2FN6yMxrpbZO6TzG 6SB5cO\%25mmd2F8xuaROMpRzzbt3fsyuBXa96 [Last accessed on May 31, 2021]

56 Chen $G$ and Goeddel DV: TNF-R1 signaling: a beautiful pathway. Science 296(5573): 1634-1635, 2002. PMID: 12040173. DOI: $10.1126 /$ science. 1071924

57 Liu W, Chen X, He Y, Tian Y, Xu L, Ma Y, Hu P, Su K, Luo Z, Wei L and Zhang J: TNF $\alpha$ inhibits xenograft tumor formation by A549 lung cancer cells in nude mice via the HIF 1 $\alpha$ /VASP signaling pathway. Oncol Rep 41(4): 2418-2430, 2019. PMID: 30816548. DOI: $10.3892 / o r .2019 .7026$

58 Yang Y, Lv SY, Ye W and Zhang L: Apelin/APJ system and cancer. Clin Chim Acta 457: 112-116, 2016. PMID: 27083318. DOI: $10.1016 /$ j.cca.2016.04.001

59 Uribesalgo I, Hoffmann D, Zhang Y, Kavirayani A, Lazovic J, Berta J, Novatchkova M, Pai TP, Wimmer RA, László V, Schramek D, Karim R, Tortola L, Deswal S, Haas L, Zuber J, Szúcs M, Kuba K, Dome B, Cao Y, Haubner BJ and Penninger JM: Apelin inhibition prevents resistance and metastasis associated with antiangiogenic therapy. EMBO Mol Med 11(8): e9266, 2019. PMID: 31267692. DOI: $10.15252 / \mathrm{emmm} .201809266$

60 Kim TW, Hong DW, Kang CM and Hong SH: A novel PPAR $\gamma$ ligand, PPZ023, overcomes radioresistance via ER stress and cell death in human non-small-cell lung cancer cells. Exp Mol Med 52(10): 1730-1743, 2020. PMID: 33046822. DOI: 10.1038/s12276-020-00511-9

61 Chang WH and Lai AG: The pan-cancer mutational landscape of the PPAR pathway reveals universal patterns of dysregulated metabolism and interactions with tumor immunity and hypoxia. Ann NY Acad Sci 1448(1): 65-82, 2019. PMID: 31215667. DOI: 10.1111/nyas.14170

62 Hazra S, Peebles KA, Sharma S, Mao JT and Dubinett SM: The role of PPARgamma in the cyclooxygenase pathway in lung cancer. PPAR Res 2008: 790568, 2008. PMID: 18769553. DOI: $10.1155 / 2008 / 790568$

$63 \mathrm{Hu}$ Z, Wang X, Yang Y, Zhao Y, Shen Z and Huang Y: MicroRNA expression profiling of lung adenocarcinoma in Xuanwei, China: A preliminary study. Medicine (Baltimore) 98(21): e15717, 2019. PMID: 31124951. DOI: 10.1097/MD.0000000000015717

64 Wu M, Wu Y, Qian H, Tao Y, Pang J, Wang Y and Chen Y: Type II cGMP dependent protein kinase inhibits the migration, invasion and proliferation of several types of human cancer cells. Mol Med Rep 16(4): 5729-5737, 2017. PMID: 28849123. DOI: $10.3892 / \mathrm{mmr} .2017 .7290$

Received May 16, 2021

Revised May 27, 2021

Accepted May 31, 2021 